\title{
Are Default Nudges Deemed Fairer When They Are More Transparent? People's Judgments Depend on the Circumstances of the Evaluation
}

\author{
Patrik Michaelsen*, Lina Nyström, Timothy J. Luke, Lars-Olof Johansson \& Martin Hedesström \\ Department of Psychology, University of Gothenburg
}

\begin{abstract}
To avoid concerns of manipulation, nudges should be transparent to the people affected by the intervention. Whether increasing the transparency of a nudge also leads to more favorable perceptions of the nudge is however not certain, and may depend on the circumstances of the evaluation. Across three preregistered experiments $(\mathrm{N}=1915)$, we study how increased transparency affects the perceived fairness of a default nudge, in joint vs. separate, and description- vs. experiencebased evaluations. We find that transparency increases perceived fairness of the nudge in a joint comparison, when the relative benefits of transparency are easy to see. However, in a real choice-context, with nothing to compare against, transparency instead decreases perceived fairness. Efforts to make nudges more ethical may thus ironically make choice architects perceived as less ethical. Additionally, we find that the transparent default nudge still successfully affects behavior, that different default-settings communicate different perceived intentions of the choice architect, and that participants consistently favor opt-in defaults over opt-out defaults nudges - regardless of their level of transparency.
\end{abstract}

Keywords: nudging; choice architecture; transparency; fairness; opt-out default

* Corresponding author. patrik.michaelsen@psy.gu.se. Twitter: @ p_michaelsen

Ideally, behavior change interventions will be both effective in changing behavior and perceived as fair and acceptable by people subjected to them. In the realm of nudges, interventions influencing behavior by changing cues in choice environments, effectiveness and acceptability may be in tension. In terms of effectiveness, no interventions outperform default nudges (Hummel \& Maedsche, 2019). However, people count defaults among the least acceptable nudge types (Hagman, Andersson, Västfjäll \& Tinghög, 2015). In the present research, we investigate whether effectiveness and acceptability can be reconciled by making default nudges transparent to decision makers. Specifically, we study how fair people judge defaults to be, if fairness perceptions can be increased by increasing intervention transparency, and whether people's judgments depend on the mode by which the nudge is evaluated.

A little more than a decade has passed since Thaler and Sunstein published the seminal Nudge (2008), a book on psychologically informed behavior change interventions and their possible usefulness in public policy. Among the many discussions it sparked, a major theme has been the legitimacy of using behavioral insights to influence people's behavior (Schmidt \& 
Engelen, 2020; Sunstein, 2016). A central ethical concern has been that (some) nudges, such as defaults, are perceived to operate outside of people's awareness (Bovens, 2009; House of Lords, 2011; Smith, Goldstein \& Johnson, 2013). If a nudge affects choices at a level below consciousness, this may be seen as manipulation, and thus as posing a threat to autonomy. Traditional forms of policy measures, such as taxation or bans, may at times restrict people's freedom of choice more than nudges do. However, since the presence and mechanisms of these interventions are easily recognizable to people, charges of manipulation are not leveled.

Higher transparency may thus be a key to increasing the ethicality and acceptability of nudges. Nudges that are not inherently transparent, such as many defaults interventions, can be made transparent by external means. For instance, written information can be provided that discloses the presence, intention behind, and expected effect of the nudge. This gives people an opportunity to spot and comprehend the nudge, making the influence no longer outside of awareness. How openly and directly available the disclosed information ought to be in order to avoid manipulation has been debated. On one account, it may suffice with a general disclosure in public records that certain nudges are in use and to what aim (cf. discussion in Thaler \& Sunstein, 2008, pp. 246-249). A stronger account may require that the nudge is possible to detect at the time of it exerting influence; either as judged by an average person or by an attentive, "watchful", average person (see Bovens 2009, and Ivankovic \& Engelen, 2019, which both argue in favor of the latter).

Not only is addressing ethical concerns important in its own right, but it may be important in promoting the social interaction taking place between the nudger and the nudgee (Krijnen, Tannenbaum \& Fox, 2017). Even if a nudge is successful in changing behavior, its use may communicate unwanted elements that render the net effect -broadly construed- lower. For instance, an intervention perceived as manipulative might negatively affect perceptions of the choice architect and erode trust in them. Contrarily, a nudge employed in a fair and transparent way could, even with limited success in changing behavior, signal respectfulness and cultivate the relationship, which in turn may further future interactions.

A burgeoning survey-literature shows that common nudges receive majority support in a wide range of countries (Hagman et al., 2015; Jung \& Mellers, 2016; Pe'er et al., 2019; Reisch \& Sunstein, 2016; Sunstein, Reisch \& Rauber, 2017). A pattern evidenced in several studies is that people prefer nudges that are transparent and target reflective thinking, as opposed to targeting subconscious psychological processes. For instance, transparent interventions have been associated with higher approval ratings, lower threat to autonomy, and lower levels of paternalism (Davidai \& Shafir, 2020; Gold, Lin, Ashcroft \& Osman, 2020; Jung \& Mellers, 2016). Further, the more the nudge is perceived to target reflective thinking, the more participants predict choices to feel authentic, and the more willing they are to work for a company employing the nudge (Felsen, Castelo \& Rainer, 2013). As posited at the outset, this hints at an acceptability problem for default nudges, as they are often perceived as nontransparent interventions. Indeed, the two default interventions researched by Hagman et al (2015) - default enlisting of organ donors, and a default to compensate carbon emissions for a flight - were the only ones to just barely receive majority support, and had more than three quarters of the sample finding them intrusive to freedom of choice.

However, an important limitation constrains the conclusions we can draw from these studies about the influence of transparency on people's perceptions of nudges: Transparency and the type of intervention have been confounded. Instead of manipulating the level of transparency for a single nudge intervention, conclusions have been arrived at from comparisons between 
transparent nudges on the one hand, and altogether different types of non-transparent nudges on the other. For instance, in one study warnings and graphic pictures of damaged lungs on cigarette packages (transparent nudge) were compared to making the filter a larger proportion of the cigarette (non-transparent nudge). Another study compared information on the benefits of enlisting as an organ donor (transparent nudge), to default enlisting as an organ donor (nontransparent nudge). While justified in drawing inferences about groups of nudges, these studies fail to illuminate how increasing transparency on its own may influence perceptions of a nudge.

Moreover, as the survey-based research paradigm uses descriptions of nudges as the stimuli for participants to rate, ratings are given without participants actually encountering the nudges themselves. Similar topics have however recently been approached by studies subjecting participants to nudges first-hand. By having participants actually make choices in environments subjected to nudges, these studies provide what may be a better indication of how real world nudge applications are perceived. In the remainder of this paper, we will refer to the former approach as a description-based evaluation mode, and the latter as an experience-based evaluation mode.

In experience-based studies, findings have arguably been somewhat more favorable for default nudges than in the description-based literature. For instance, in a hypothetical apartment acquisition scenario, Steffel, Williams, and Pogacar (2016) showed that participants perceived being nudged towards pro-environmental amenity choices to be fair (vs. unfair). In an actual (as opposed to hypothetical) charity donation choice, Michaelsen, Johansson and Hedesström (2020) found decidedly low objection ratings to the choice format (mean ratings 2.6 on a 9-point scale), even though participants were nudged to give away money. In this study, participants subjected to the opt-out default (i.e., the nudge) and those subjected to an opt-in default (i.e., defaulted to keeping the money for oneself) gave virtually indistinguishable ratings of how much they objected the intervention.

In contrast to the description-based paradigm, experience-based studies have also investigated effects of increasing the transparency for one and the same nudge. Interestingly from an ethical viewpoint, transparency has been increased to make the nudge easily detectable in the moment of exerting influence, by presenting a disclosure statement explaining the nudge to participants in conjunction with them making their decision. Even such immediate nudge disclosures have been shown to have a very small, or no, diminishing effect on the effectiveness of the nudge (Bruns et al., 2018; Loewenstein et al., 2015; Michaelsen, Johansson \& Hedesström, 2020; Steffel et al., 2016; Paunov, Wänke \& Vogel, 2019; Wachner, Adriaanse \& De Ridder, 2020).

Increasing the transparency of a nudge also seems to have no or negligible negative effects on people's experiences and perceptions of the nudge. For instance, experience-based studies have found that making a default nudge transparent entailed no or minor increase in perceived threat to freedom of choice (Michaelsen et al., 2020) and experienced autonomy (Michaelsen et al., 2020; Wachner et al., 2020). Paunov et al. (2019) further showed that making a default nudge transparent can lead to lower feelings of being deceived.

At present, it appears unclear exactly why people seem more positive towards nudges in an experience-based evaluation mode, as compared to in a description-based mode. One possibility is that the nudge simply is found less intrusive than expected once actually encountered. Another possibility is that apparent differences between evaluation modes primarily reflect differences in operationalization and measurement, rather than substantive effects, as few direct comparisons have been made. 
In sum, people seem to perceive nudges differently depending on in which evaluation mode their judgments are elicited. This has important consequences for how people's opinions on nudges should be assessed, as one and the same nudge may be considered acceptable when judged in one mode, but unacceptable when judged in another. Thus, policy decisions guided by only a single perspective risk misrepresenting the public perception. To the best of our knowledge, no studies have systematically investigated the consistency, or lack thereof, of nudge perceptions across both description-based (nudge rated after reading a description) and experience-based (nudge rated after making a choice subjected to a nudge intervention) evaluation modes (but see Bang, Shu \& Weber, 2020; Davidai \& Shafir, 2020).

It can similarly be expected that increasing the transparency of a nudge is perceived differently between evaluation modes. Additionally, much is left unanswered as to whether increased transparency can better the public's view on nudges, since the dominant, descriptionbased, research-paradigm for studying people's perceptions of nudges have confounded level of transparency with type of nudge.

Thus, in the present paper we set out to accomplish three goals: 1) systematically compare perceptions of opt-in and opt-out defaults across description- and experience-based evaluation modes, 2) test whether making one-and-the-same opt-out default nudge transparent benefits how the intervention is perceived, and 3) investigate whether increased transparency is perceived differently across different evaluation modes. This is researched in three preregistered studies (total $N=1915$ ). Specifically, we study people's fairness perceptions for three choice formats: an opt-in default, an opt-out default nudge, and a transparent opt-out default nudge, for one-and-the-same donation choice scenario, and across three evaluation modes. In Study 1 ( $n=$ 439), choice formats are compared side by side in a description-based joint comparison format. Study $2(n=424)$ employs a description-based separate evaluation. Finally, Study $3(n=1052)$ uses an experience-based evaluation format, where participants assess the choice formats after having experienced one of them first-hand by actually making a decision in the scenario. Study 3 also provides the highest-powered test to date of whether making a nudge transparent affects its effect on a consequential (monetary) choice.

\section{Study 1: Description-Based Joint Evaluation}

In a joint evaluation format, participants rate either a transparent (explicitly disclosed) opt-out default nudge side by side with a "standard" (i.e. non-disclosed) opt-out default nudge, or the standard opt-out default nudge side by side with an opt-in default. Previous research has shown that when evaluated jointly, transparent ("system 2") educational nudges receive higher support and are judged less paternalistic, than non-transparent ("system 1") opt-out default nudges (Davidai \& Shafir, 2020). Here we extend by keeping the type of nudge constant, in order to isolate the influence of increased transparency. The preregistration of this study, along with analysis code, stimulus material and data can be found at https://osf.io/fa9xv.

\section{Method}

\section{Participants}

Participants were recruited through Amazon Mechanical Turk (MTurk; www.mturk.com), and paid $\$ 0.45$ for their time. After excluding participants failing a comprehension check $(22.7 \%$ of 
finished participants failed) our final sample consisted of 439 participants $(M=39.13$ years old, $S D=12.96 ; 45.8 \%$ women). Due to more people failing the comprehension check than expected (a pilot study, $n=122$, had suggested $15 \%$ ) the final sample was slightly smaller than the 480 expected in the preregistration. A sensitivity analysis showed that the final sample was however still sufficient to detect differences corresponding to a Cohen's $d$ of 0.20 , with $80 \%$ power and $\alpha$ $=.05$, in our lowest-powered hypothesis test.

\section{Design, Outcomes and Procedure}

Participants' task was to rate choice formats, meaning ways of designing and presenting a choice task to a decision maker. Ratings were given in a joint evaluation format. Specifically, each participant separately rated two choice formats displayed to them simultaneously, side by side. ${ }^{1}$ There were two sets ("pairs") of choice formats, and each participant viewed only one. Pair 1 consisted of an opt-in default format and an opt-out default format. Pair 2 consisted of an opt-out default presented with, and without, an accompanying message disclosing the presence and expected influence of the intervention. The opt-out format without the disclosure message was identical to the opt-out format in Pair 1. In both pairs, the differences between the two presentation formats were highlighted in yellow color to facilitate comparison (screenshots are provided in the Supplementary Materials). In the remainder, we will refer to the opt-out format without a disclosure as "standard opt-out default", and the version with a disclosure present as "transparent opt-out default". The choice described in the vignettes was the same in all instances, and concerned keeping or donating a $20 \notin$ bonus payment to a pediatric cancer charity foundation. Participants did not themselves make the donation choice, their only task was to evaluate the presentation formats.

The primary evaluation of interest was the perceived fairness of the choice architecture. Specifically, participants indicated their agreement with the statement "The way in which the choice was presented was fair" on a seven-point scale, ranging from 1 (Strongly disagree) to 7 (Strongly agree). Ratings were given separately for each of the two choice architectures displayed. In order to clarify the question's focus, we instructed participants that "the questions below concern your perception of how the choice is formatted. We ask you to not judge e.g. that a bonus was given, or the specific charity cause."

We posed two confirmatory hypotheses and one open-ended research question:

Hypothesis 1: A standard opt-out default nudge will be perceived as less fair compared to an opt-in default.

Hypothesis 2: A standard opt-out default nudge will be perceived as less fair compared to a transparent opt-out default that explicitly discloses the presence and expected effect of the nudge.

Open-ended research question: Will different comparison points affect the absolute fairness ratings of an opt-out default nudge? In other words, will there be a between-groups difference in fairness ratings for the opt-out default nudge, depending on whether it was compared with a standard opt-in default or a transparent opt-out default?

\footnotetext{
${ }^{1}$ The image file containing both choice architectures was displayed at $1200 \times 575$. A pilot test had indicated this display size was easy for participants to view, and in the current sample $>98 \%$ used a screen resolution wide enough that no sideways scrolling would be needed.
} 
The questionnaire further included some exploratory measures. We measured participants' agreement with four statements on perceived intentions behind the choice architect's selection of choice format. Specifically, we measured agreements with: "The way in which the choice was presented was... 1) ...intended to influence the likelihood of donating, 2) ...intended to suggest a course of action, 3) ...intended to make choosing easy, and 4) ...intended to inform the chooser sufficiently". Order of items was randomized, and ratings were given on a seven-point scale from 1 (Strongly disagree) to 7 (Strongly agree).

Additionally, we asked participants to imagine they would be confronted with making the choice themselves. We then asked 1) which presentation format they would prefer to be presented with, 2) whether the presentation format would affect how positively they viewed the choice architect, 3) whether the choice of presentation format would affect their willingness to work with the choice architect again in the future (7-point bipolar scales, with endpoints anchored preference for format 1 - format 2), and 4) whether they thought they would choose to donate the money (separately for each presentation format).

We explained to participants that the purpose of the study was to inform our design of a future study on MTurk. In the first section of the study, participants were displayed the two presentation formats and instructed to carefully read them through. Display order, left-right presentation, for the two formats were counterbalanced. Next followed two pages containing the outcome variables described above. Each page had the presentation formats displayed at the top of the page as a reminder. The items on fairness of choice format and perceived intentions of the choice architect were asked on the first page, remaining items on the second. Lastly, participants answered a brief demographics section.

\section{Results}

\section{Perceptions of fairness}

In support of Hypothesis 1 , when jointly comparing a standard opt-out default nudge and an optin default, participants perceived the opt-out as less fair than the opt-in, paired $t(207)=9.06, p<$ $.001, d=0.79,95 \%$ CI $[0.59,0.99]$. Both choice architectures were rated positively on the scale, with the opt-out default just crossing the neutral midpoint $(M=4.67, S D=1.82)$, and the opt-in situated well above $(M=5.91, S D=1.21)$.

In support of Hypothesis 2, when jointly comparing the standard and the transparent optout default nudge, participants perceived the standard opt-out default as less fair than the transparent opt-out, paired $t(230)=2.57, p=0.01, d=.22,95 \%$ CI [0.05, 0.38]. Both choice architectures were rated positively on the scale (standard opt-out $M=5.00, S D=1.61$; transparent opt-out $M=5.35, S D=1.64$ ).

For our open-ended research question, the standard opt-out default was perceived as more fair when displayed next to the transparent opt-out default $(M=5.00, S D=1.64)$, than when displayed next to an opt-in default $(M=4.67, S D=1.82)$, independent $t(416.08)=2.01, p=.045$, $d=0.19,95 \%$ CI $[0.01,0.38]$.

\section{Exploratory analyses}

Results for the measures for perceived intentions of the choice architect, and participants' own expected donation choice, are presented in Table 1. All intention-measures were significantly 
different within each pair (row 1 vs 2 ; row 3 vs 4 ), paired t-tests, all $p s \leq .001$. Despite being rated as more fair, the transparent opt-out default was to a higher degree perceived as intended to influence the chooser than the standard opt-out default was. Presumably, the high level of perceived intended transparency ("inform the chooser sufficiently") compensated for other negative influences on the fairness assessment. Participants' expectation of whether they themselves would have donated did not differ significantly between choice formats.

Recall that participants were asked to imagine they were making the decision themselves for a series of exploratory items. In response to these items, participants' ratings were similar to their fairness ratings, thus corroborating Hypotheses 1 and 2. For each of these items, participants were asked to express their preferences on a 7-point bipolar scale, with each endpoint of the scale corresponding to a preference for one of the choice formats (or the person using them). In Pair 1, values below 4 indicate support for the opt-in default format. In Pair 2, values above 4 indicate support for the transparent opt-out default format. For each item, we compared the mean rating against the neutral midpoint of the scale (4).

In Pair 1, participants stated a preference to be presented with the opt-in format over the standard opt-out format $(M=2.50, S D=1.98, p<.001)$, would think more positively of the choice architect using an opt-in format $(M=3.01, S D=1.83, p<.001)$, and were more willing to work with the choice architect using an opt-in again in the future $(M=3.12, S D=1.71, p<$ .001). In Pair 2, participants preferred the transparent opt-out format over the standard opt-out format, albeit to a lesser magnitude. Specifically, they preferred being presented with the transparent format $(M=4.36, S D=2.45, p=.027)$, perceived the choice architect more positively $(M=4.36, S D=2.2, p=.019)$, and would be more willing to work with this choice architect again in the future $(M=4.39, S D=2.11, p<.001)$.

\section{Discussion}

Study 1 showed that participants perceived an opt-in default as more fair than a corresponding opt-out default nudge. However, if subjected to an opt-out default nudge, participants considered the choice architecture as more fair when the presence and expected influence of the nudge was made transparent by explicitly disclosing this to them.

This finding extends previous research finding that people prefer transparent types of nudges over non-transparent types of nudges (e.g. Gold et al., 2020), by evidencing that also a specific instance of a nudge is perceived more favorably when made transparent.

While increased transparency had the dual effect of increasing both perceived intended influence and sufficient informing, the latter seemingly outweighed the former in relevance for the fairness ratings. Presumably, the joint evaluation format presented participants with a reference point such that the disclosure statement appeared as an ethical improvement over the non-disclosed format (cf. Hsee, 1996; Hsee, Loewenstein, Blount \& Bazerman, 1999). We turn next to whether the benefit of added transparency remains when interventions are evaluated separately. 
Table 1. Descriptive statistics for main outcomes, Study 1.

\begin{tabular}{|c|c|c|c|c|c|c|c|}
\hline & & Fairness & $\begin{array}{l}\text {...intended to } \\
\text { influence the } \\
\text { likelihood of } \\
\text { donating }\end{array}$ & $\begin{array}{l}\text {...intended } \\
\text { to suggest } \\
\text { a course of } \\
\text { action }\end{array}$ & $\begin{array}{c}\text {...intended } \\
\text { to make } \\
\text { choosing } \\
\text { easy }\end{array}$ & $\begin{array}{c}\text {...intended } \\
\text { to inform the } \\
\text { chooser } \\
\text { sufficiently }\end{array}$ & $\begin{array}{l}\text { Predicted } \\
\text { hemselves } \\
\text { would } \\
\text { donate }\end{array}$ \\
\hline & $\begin{array}{l}\text { Opt-in default } \\
n=208\end{array}$ & $\begin{array}{c}5.91 \\
(1.21)\end{array}$ & $3.76(1.89)$ & $4.65(1.70)$ & $5.31(1.42)$ & $5.75(1.28)$ & $36 \%$ \\
\hline ב & $\begin{array}{l}\text { Standard opt-out } \\
\text { default } \\
\text { (vs. opt-in) } \\
n=208\end{array}$ & $\begin{array}{c}4.67 \\
(1.82)\end{array}$ & $6.11(1.33)$ & $5.85(1.41)$ & $4.55(1.84)$ & $5.15(1.64)$ & $41 \%$ \\
\hline \multirow{2}{*}{ 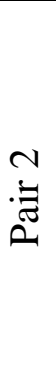 } & $\begin{array}{l}\text { Standard opt-out } \\
\text { default } \\
\text { (vs. transparent) } \\
n=231\end{array}$ & $\begin{array}{c}5.00 \\
(1.61)^{1}\end{array}$ & $4.89(1.76)$ & $4.95(1.68)$ & $4.86(1.64)$ & $4.60(1.70)$ & $50 \%$ \\
\hline & $\begin{array}{l}\text { Transparent opt- } \\
\text { out default, } \\
n=231\end{array}$ & $\begin{array}{c}5.35 \\
(1.64)\end{array}$ & $5.70(1.59)$ & $5.75(1.47)$ & $\begin{array}{c}5.35 \\
(1.57)^{1}\end{array}$ & $5.87(1.43)$ & $53 \%$ \\
\hline
\end{tabular}

Note: For Likert-type items, numbers refer to means and standard deviations. All intention-measures are significantly different within each comparison (row 1 vs 2; row $3 v_{s} 4$ ), at $p \leq .001$, in paired samples t-tests. Predicted donation is not significantly different within either pair.

${ }^{1} n=230$

\section{Study 2: Description-Based Separate Evaluation}

Study 2 employs a between-groups design using the same choice formats and main dependent variables as Study 1. Thus, instead of evaluating a pair of default choice formats, participants evaluate only one format. This design can be viewed as a harder test of the hypotheses posed in Study 1 (although not necessarily a more "correct" test), as there is no reference point facilitating gauging the choice formats' merits and drawbacks. Previous research has shown that integral features of an opt-in default are sufficiently discernable, in a between-groups design, for participants to judge it as more ethical than a transparent opt-out default nudge (Yan \& Yates, 2019). However, the second focus of this paper, whether it is possible to make one-and-the-same opt-out default nudge be perceived more favorably by increasing its transparency, has previously not been researched. The preregistration of this study, along with analysis code, stimulus material and data can be found at https://osf.io/fa9xv. 


\section{Method}

\section{Participants}

Participants were recruited through MTurk, and paid $\$ 0.40$ for their time. As preregistered, we requested 660 completed surveys, expecting a sample of 528 participants after exclusions. More participants than expected failed our attention check however, leaving us with a final sample of 424 participants $(M=39.4$ years old, $S D=13.2 ; 49.5 \%$ women $)$. A sensitivity analysis showed that the final sample was sufficient to detect differences corresponding to a Cohen's $d$ of 0.34 , with $80 \%$ power and $\alpha=.05$, in our lowest-powered hypothesis test.

\section{Design, Outcomes and Procedure}

Materials were virtually identical to in Study 1, but changed into a between-groups design. Additionally, a few exploratory measures were dropped. Instead of viewing and evaluating a pair of choice formats, participants viewed and evaluated only one format, either: an opt-in default, a standard (i.e. un-disclosed) opt-out default nudge, or a transparent opt-out default nudge with the presence and expected influence of the intervention explicitly disclosed. As participants were only displayed one choice format, there was no colored highlighting of differences between choice formats, as was used in Study 1 (screenshots are provided in the Supplementary Materials).

Participants rated the fairness of the choice architecture and four perceived intentions behind the choice architect's selection of choice format. They were also asked to predict whether they would have donated the money had they encountered the choice themselves. All measures were set up as described in Study 1. We again reminded participants that the questions concerned their perception of how the choice was formatted, and not of the fact that a bonus was given, or of the specific charity cause.

We posed the same two confirmatory hypotheses as in Study 1:

Hypothesis 1: An opt-out default nudge will be perceived as less fair compared to an opt-in default.

Hypothesis 2: A standard opt-out default nudge will be perceived as less fair compared to a transparent opt-out default that explicitly discloses the presence and expected effect of the nudge.

\section{Results}

\section{Perceptions of fairness}

We tested both hypotheses using a linear regression model with perceived fairness predicted by experimental condition, and the opt-out default condition set as reference group. In support of hypothesis 1 , fairness ratings were higher for the opt-in default $(M=5.95, S D=1.22)$ than for the standard opt-out default nudge $(M=4.56, S D=1.69), b=1.39, S E=0.19, p<.001, d=0.93$, 95\% CI [0.68, 1.17]. Hypothesis 2 was however not supported, as there was no significant difference in fairness ratings between the standard and the transparent opt-out default nudge $(M$ $=4.63, S D=1.80), b=0.07, S E=0.19, p=.709, d=0.004,95 \%$ CI $[-0.19,0.27]$. 


\section{Exploratory analyses}

As can be seen in Table 2, participants perceived different intentions behind the default formats in separate evaluation as well. As in Study 1, the opt-in default stood out and was significantly different from both opt-out conditions for all intention-measures (all $p$ s <.01, Tukey HSD). The differences between the standard and transparent opt-out formats diminished in comparison to in Study 1, however. There was a hint of the disclosure leading to an increase in perceived intended influence, $t(282.4)=2.26, p=.025, d=0.27,95 \%$ CI $[0.03,0.50]$, however the effect was not strong enough to be significant when controlling for multiple testing. No other comparisons between the standard and transparent opt-out default conditions were significant.

Table 2. Descriptive statistics for main outcomes, Study 2.

\begin{tabular}{lcccccc}
\hline & & $\begin{array}{c}\text {..intended to } \\
\text { influence the } \\
\text { likelihood of } \\
\text { donating }\end{array}$ & $\begin{array}{c}\text {...intended } \\
\text { to suggest } \\
\text { a course of } \\
\text { action }\end{array}$ & $\begin{array}{c}\text {...intended to } \\
\text { make } \\
\text { choosing } \\
\text { easy }\end{array}$ & $\begin{array}{c}\text {...intended } \\
\text { to inform the } \\
\text { chooser } \\
\text { sufficiently }\end{array}$ & $\begin{array}{c}\text { Predicted } \\
\text { themselves }\end{array}$ \\
\hline $\begin{array}{l}\text { Opt-in } \\
\text { default } \\
n=135\end{array}$ & $\begin{array}{c}5.95 \\
(1.22)\end{array}$ & $3.59(1.91)$ & $4.26(1.98)$ & $5.50(1.35)$ & $5.50(1.40)$ & $38 \%$ \\
$\begin{array}{l}\text { Standard } \\
\text { opt-out } \\
\text { default }\end{array}$ & 4.56 & $5.76(1.37)$ & $5.81(1.24)$ & $4.69(1.76)$ & $4.76(1.60)$ & $56 \%$ \\
$n=153$ & $(1.69)$ & & & & & \\
$\begin{array}{l}\text { Transpare } \\
\text { nt opt-out } \\
\text { default, } \\
n=136\end{array}$ & 4.63 & $6.12(1.38)$ & $6.04(1.34)$ & $4.81(1.86)$ & $4.92(1.60)$ & $52 \%$ \\
\hline
\end{tabular}

Note: For Likert-type items, numbers refer to means and standard deviations. For all intentionmeasures, the opt-in default is significantly different from both opt-out defaults, all ps <.01 (Tukey HSD). For predicted own donation, both opt-out defaults are significantly higher than the opt-in default in a logistic regression model, $p s \leq .017$.

\section{Discussion}

Study 2 found that in a separate evaluation, participants perceived the opt-in format as more fair than both the standard and transparent opt-out format. People may have an intuitive, or prior, understanding of the default effect (see Jung, Sun \& Nelson, 2018, and Zlatev, Daniels, Kim \& Neale, 2017), such that an explicit reference point (as provided in Study 1's joint evaluation format) is not needed to understand the opt-out default as trying to solicit a certain behavior. The sizeable difference in how people perceived the choice architect's intention to influence them is compatible with this interpretation, and similarly are the results for the other intention-measures 
and participants' self-predicted donation behavior (see Table 2). On this interpretation, a common opt-out default nudge may not be as inherently non-transparent as is sometimes feared (Bovens, 2009). However level of transparency will necessarily vary with choice context.

Increasing the transparency of the opt-out default nudge did not increase fairness perceptions. An examination of the intention-measures show that perceived intention to influence, and intention to suggest a course of action, were very high in the transparent opt-out default condition. However, intention to sufficiently inform the chooser dropped a scale point compared to in Study 1. Thus, with no undisclosed "counterfactual" present, the disclosure seemingly failed to mitigate perceptions of the influence attempt as negative.

Having elicited fairness perceptions in joint and separate description-based evaluations in the first two studies, we lastly turn to actually subjecting people to the nudge in order to assess whether the pattern of results so far transfer to a genuine application.

\section{Study 3: Experienced-Based Separate Evaluation}

In Study 3, evaluation mode is changed from the previous studies' description-based mode, into an experienced-based mode. In other words, participants are subjected to the same donation choice scenario (formatted as opt-in, standard opt-out, or transparent opt-out) described in the previous studies, and make a decision before rating the fairness of the nudge. Apart from perceptions of fairness, we also look at how transparency affects participants' choice of whether or not to donate. In an equivalence test, we formally test whether the effect on choice can be considered statistically negligible, as suggested by previous research (Bruns et al., 2018; Loewenstein et al., 2015; Michaelsen, et al., 2020; Steffel et al., 2016; Wachner et al., 2020). The preregistration of this study, along with analysis code, stimulus material and data can be found through https://osf.io/fa9xv.

\section{Method}

\section{Participants}

Participants were recruited through MTurk, and paid $\$ 0.35$. After attention check exclusions, the sample consisted of 1052 participants $(M=38$ years old, $S D=12.7 ; 54.4 \%$ women). This was close to our preregistered target of 1053 participants, and corresponds to $80 \%$ power to detect differences of $d=0.21$ in a between-groups t-test, with a significance level of .05 . A total of 555 participants were excluded for failing an "instructional manipulation check" (IMC;

Oppenheimer, Meyvis, \& Davidenko, 2009), and 80 participants were excluded for misreporting whether or not they had chosen to donate a bonus payment in the experiment's main choice task.

\section{Design, Outcomes and Procedure}

The study was advertised as being on comparisons of geometrical shapes. Participants rated the similarity between six pairs of shapes before the actual experiment began. The IMC consisted of an extension to the instructions of the shapes task. Participants who read the instructions hastily were led to believe that for the next shape comparison, they should also account for similarity in color. Attentive participants, reading the instructions to the end, instead learnt that they were asked to check a specific scale point and write a +-sign in a text field. 
After completing the shapes comparisons, the actual experiment began. In the experimental choice task, participants faced the donation choice used as a vignette in the two previous studies. Instead of rating a description of the choice formats, participants were asked to make the decision between donating a $20 \notin$ bonus to a pediatric charity organization or keeping it for themselves, and afterwards rated the choice format. The donation choice was presented identically to in the three choice formats used in the previous experiments. Participants faced either an opt-in default, an opt-out default nudge, or a transparent opt-out default nudge with the presence and expected effect of the intervention explicitly disclosed. Subsequent to making the donation choice participants answered questions on perceived fairness. In order to filter out aspects of participants' fairness perceptions, we asked the following threefold question: "To what extent do you perceive that... 1) ... offering you the bonus was fair?, 2) ... offering you the option to donate the bonus was fair?, and 3) ... the two choice options (to KEEP or to DONATE) were presented to you in a fair way?". As preregistered, our focus was only on the third item, and it is the one used in the analyses below. Answers were given on a seven-point scale anchored "Completely unfair" and "Completely fair". Each scale step was labelled numerically, from -3 through to 3 .

We posed five hypotheses and one open-ended research question:

Hypothesis 1: Participants in the standard opt-out condition will donate to a higher degree than participants in the opt-in condition.

Hypothesis 2: Participants in the transparent opt-out condition will donate to a higher degree than participants in the opt-in condition.

Open-ended research question: Will the strength of the default effect be moderated by participants' attentiveness (as measured by passing or failing the IMC)?

Hypothesis 3: Donations in the standard opt-out condition and the transparent opt-out condition will be statistically equivalent (with equivalence bounds set at $\mathrm{a}+/-.08$ difference in proportions)

Hypothesis 4: Participants subjected to a transparent opt-out default will perceive the choice format as fair (above neutral midpoint of scale).

Hypothesis 5: Participants in the transparent opt-out condition will perceive the choice format as more fair than participants in the standard opt-out condition.

As an exploratory matter, we further asked "To what extent did you feel as if you were expected to donate the $20 \notin$ bonus?" ( 1 - Not at all to 7 - Completely), "Of all participants taking part in this survey, how many do you think will choose to donate the $20 \notin$ bonus?" $(0-100 \%)$. At the end of survey, we also included an exploratory measure of possible behavioral spillover from the default-settings. These results are reported elsewhere (Hedesström et al., 2020). 


\section{Results}

\section{Donation choice}

We tested Hypotheses 1 and 2 in a logistic regression model with dummy codes for the two optout conditions, and the opt-in condition as reference group. Both hypotheses were supported. Specifically, we found support for a default effect in that $47.1 \%$ of participants in the standard opt-out default condition choose to donate their bonus, which was significantly more than the $26 \%$ of participants subjected to the opt-in default (Hypothesis 1 ), Wald $(1),=32.85$, OR $=2.54$, $p<.001$. Similarly, participants subjected to the transparent opt-out default were significantly more likely to donate their bonus $(53.1 \%)$, than participants in the opt-in condition (Hypothesis 2 ), $\operatorname{Wald}(1)=52.30, \mathrm{OR}=3.22, p<.001$. The difference in donation rates was not significantly different between the standard and transparent opt-out conditions, $p=.113$ (see also Hypothesis 3 below). With regards to the open-ended research question, there was no evidence that attention, as measured by passing or failing the IMC, moderated the strength of the default effect. Neither interaction with the two opt-out conditions was significant, $p \mathrm{~s}>.25$. Passing the IMC did not itself predict donation rate, $p=.91$.

Hypothesis 3, predicting donation rates in the standard and transparent opt-out conditions to be of equivalent size, was not supported. We used a TOST equivalence test (Lakens 2017; Lakens, Scheel, \& Isager, 2018), with equivalence bounds set at a +/- .08 difference in proportions. $^{2,3}$ The analysis showed the transparent opt-out condition to be significantly higher than the low equivalence bound, $Z_{\text {low }}=3.71, p<.001$, but not significantly lower than the high bound, $Z_{\text {high }}=-.54, p=.296$. In other words, donations in the standard and transparent opt-out conditions were not statistically equivalent due participants in the transparent condition donating too much.

\section{Perceptions of fairness}

In support of Hypothesis 4, participants subjected to a transparent opt-out default nudge perceived the choice format as fair (vs. unfair). This was tested with a one-sample t-test, which showed that participants' average fairness rating of $5.89(S D=1.66)$ was significantly higher than the neutral midpoint of the scale $(4)^{4}, t(353)=21.45, p<001$.

Next, we analyzed whether the transparent opt-out default was perceived as more fair than the standard opt-out default. In opposition to Hypothesis 5 however, an independent samples t-test showed that the transparent opt-out default $(M=5.89, S D=1.66)$ was perceived as significantly less fair than the standard opt-out default $(M=6.22, S D=1.39), t(683.17)=2.88, p$ $=.004, d=0.22,95 \% \mathrm{CI}[0.07,0.38]$. An inspection of the frequency distributions showed no evidence of the result being driven by a sub-group of participants reacting strongly against the transparent opt-out default nudge (see Supplementary Materials, Figure 3). Rather, the mean

\footnotetext{
2 The TOST-procedure consists of running two one-sided tests assessing whether an effect is weaker than a specified upper and lower smallest effect size of interest, in which case equivalence is declared.

${ }^{3}$ Equivalence bounds were not based on theoretical reasoning, but on what we had approximately $80 \%$ power to detect in the analysis.

${ }^{4}$ Our preregistered analysis code incorrectly specified the midpoint of the scale as " 0 ", which did not correspond to how the scale was coded. As the preregistration explicitly references "the midpoint of the scale", we report only the corrected analysis.
} 
difference reflected a small but noticeable shift towards lower ratings consistently across the scale.

\section{Exploratory analyses}

We analyzed whether the perceived fairness of the opt-in default format differed from the two opt-out formats, using analysis of variance and Tukey HSD. Results showed that the opt-in format $(M=6.37, S D=1.20)$ was perceived as significantly more fair than the transparent optout format $(p<.001)$, but not significantly different from the standard opt-out format $(p=.36)$, $F(2,1048)=10.4, p<.001$.

Finally, participants in the standard opt-out $(M=4.46, S D=2.05)$ and transparent opt-out $(M=4.63, S D=2.12)$ conditions felt a higher expectation to donate their bonus as compared to participants in the opt-in condition $(M=3.77, S D=2.13), F(2,1049)=16.82, p<.001, \eta p^{2}=$ .019. Participants' estimations of how many percent of others would donate tracked actual donations well: standard opt-out $(M=56.1)$, transparent opt-out $(M=56.4)$, opt-in $(M=44.5)$.

Table 3. Descriptive statistics for main outcomes, Study 3.

\begin{tabular}{lcccc}
\hline & & & $\begin{array}{c}\text { Felt } \\
\text { expectation to } \\
\text { donate }\end{array}$ & $\begin{array}{c}\text { Estimated \% of } \\
\text { others that would } \\
\text { donate }\end{array}$ \\
\hline $\begin{array}{l}\text { Opt-in default } \\
n=350\end{array}$ & $26 \%$ & $6.37(1.20)$ & $3.77(2.13)$ & $44.5 \%$ \\
$\begin{array}{l}\text { Standard opt-out default } \\
n=348\end{array}$ & $47.1 \%$ & $6.22(1.39)$ & $4.46(2.05)$ & $56.1 \%$ \\
$\begin{array}{l}\text { Transparent opt-out default, } \\
n=354\end{array}$ & $53.1 \%$ & $5.89(1.66)$ & $4.63(2.12)$ & $56.4 \%$ \\
\hline
\end{tabular}

\section{Discussion}

Study 3 investigated whether increasing the transparency of an opt-out default nudge would increase the perceived fairness of the nudge when people are subjected to the nudge first-hand, and whether the transparent nudge would still successfully affect choices.

As hypothesized, participants experiencing the transparent opt-out default nudge firsthand rated this choice format as fair. Nevertheless, and counter to our prediction, increasing the transparency of the nudge led to a decrease in perceived fairness. The decrease in fairness runs counter to the intention behind disclosing a nudge in the first place, and stands in contrast to previous studies documenting positive effects of disclosing nudges (e.g. Paunov et al., 2019). However, there are plausible explanations for the observed negative effect on perceived fairness. The choice participants faced was a trade-off between keeping and giving away money, and the nudged course of action was to donate the money. This is counter to most people's immediate self-interest, and previous research shows that such nudging is rated among the most intrusive, and least acceptable (Jung \& Mellers 2016; Hagman et al., 2015). The disclosure may then have 
succeeded in increasing the transparency of the nudge, but instead of communicating openness, it may (also) have functioned as a signal that influence was attempted.

The disclosure did, however, not decrease the effectiveness of the opt-out default nudge in affecting choice. Regardless of being disclosed or not, participants in the nudge conditions were about twice as likely to donate their bonus endowment to charity compared to participants in the opt-in default condition. This finding supports the general conclusion of previous studies on disclosing default nudges, that increased transparency has no, or a very small, diminishing effect on behavior (Bruns et al., 2018; Loewenstein et al., 2015; Michaelsen, et al., 2020; Steffel et al., 2016; Wachner et al., 2020). Study 3 contributes to this literature by evidencing the same finding using demonstrably attentive participants, in a high-powered experiment, and with a monetary choice. While statistical equivalence between donations in the standard and transparent opt-out default nudge conditions was not evidenced, it should be reiterated that this was due to participants in the transparent opt-out condition donating to a higher degree than participants in the non-transparent condition (cf. Paunov et al., 2019).

\section{General Discussion}

The main focuses of this paper was to 1) systematically compare perceptions of opt-in and optout defaults across description- and experience-based evaluation modes, 2) test whether making an opt-out default nudge transparent benefits how the intervention is perceived, and 3) investigate whether increased transparency is perceived differently across different evaluation modes. We found that across evaluation modes, participants were highly consistent in rating an opt-in default format as more fair than an opt-out format, even when the latter was made transparent. Evaluation mode did, however, change how increased transparency was perceived for the opt-out default nudge, and was found to both increase and decrease the fairness of the choice format. Specifically, increased intervention transparency led to an increase in fairness ratings when a standard, undisclosed, version of the nudge was provided as a reference point (Study 1). The increase vanished without a reference point however (Study 2), and when the nudge was experienced first-hand in an actual choice, the transparent opt-out was perceived as less fair than a standard opt-out default (Study 3).

Additionally, to our knowledge, Study 3 provides the highest-powered test to date of whether increased transparency influences the effectiveness of an opt-out default nudge in a costly choice. In contrast to postulates that nudges "work best in the dark" (Bovens, 2009, p. 13), results showed that the opt-out default nudge was similarly effective in changing behavior after having been disclosed to the decision maker.

From a bird's eye view, our findings are similar to those of previous studies on people's perceptions of nudges. We corroborate that default nudges are perceived as largely acceptable, but that people have concerns about being influenced (cf. Hagman et al., 2015; Jung \& Mellers, 2016; Yan \& Yates, 2019). Likewise, we corroborate that default nudges can be disclosed to decision makers without losing their effectiveness (Bruns et al., 2018; Loewenstein et al., 2015; Michaelsen, et al., 2020; Steffel et al., 2016; Wachner et al., 2020). However, upon closer inspection, an important difference emerges in that transparency is demonstrated to not be an unambiguous asset for a nudge. Instead, when keeping the type of nudge constant (i.e. not comparing across different types of nudges), transparency's influence on perceptions of the nudge depended on in which evaluation mode participants perceptions were elicited. 
It is interesting that mode of evaluation could change how transparency affected the perceived fairness of an opt-out default nudge in both directions, but showed such little effect on how the fairness of opt-in vs standard opt-out default formats were perceived. We interpret this as the qualities of the opt-in and standard opt-out formats being intuitive enough for participants to grasp, whereas an increase in intervention transparency was not itself enough make the intervention appear more fair, but needed a reference point to be appreciated (cf. research on joint vs. separate evaluation; Hsee, 1996; Hsee, Loewenstein, Blount \& Bazerman, 1999). With a standard opt-out presented as a baseline, the otherwise hard-to-judge merits of the nudge disclosure stood out and made providing it seem honest and fair. Without a comparison point, the disclosure was instead seen as a part of the influence attempt (see perceived intended influencemeasure in Table 2), and was perceived in a less positive way.

That the negative effect of increased transparency occurred only when participants experienced the nudge first-hand (Study 3), and not the description-based mode (Study 2), may be explained by the experience-mode leading to a higher engagement with the choice. In both studies 1 and 2, there was a tendency to see the choice architect as to a higher degree trying to exert influence on them when the nudge was transparent. Possibly first when experienced, with money on the line, the perceived intended influence became strong enough to actually decrease fairness ratings.

We hesitate to argue that one evaluation mode holds strict precedence over the other concerning people's opinions and perceptions of a nudge. Both description- and experiencebased approaches can elicit valid and informative evaluations, and each approach comes with separate merits and drawbacks. On the one hand, people may have an easier time to take a step back and reflect on their judgment when evaluating a nudge in a description-based format. This is especially likely if the evaluator is presented with a comparison point, such as in a joint evaluation format. On the other hand, an experienced-based approach is by definition better suited for answering how a nudge is perceived by people in the "heat of the moment", in a real world application. This mode may pick up nuance that is lost when a nudge is rated at a distance, based on a description. We thus recommend that policy-makers and other choice architects gather public opinion in multiple ways, in order to be able to design policies that best meet the public's expectations. This is especially the case when the intervention contains elements that may be hard to assess, such as when making a nudge transparent by providing a nudge disclosure. One way to reap the benefits of both approaches could be to use the description-based survey approach as an avenue for developing models of what affects people's perceptions of nudges (see Hagman, 2018), and experience-based studies as a stress test of theory before interventions are converted into larger-scale policy.

Concerning generalizability, it should be remembered that only one type of nudge was tested in the present studies. While we see little reason that our findings should not extend to other types of nudges, the substantive findings are necessarily affected by the specific context. It is also conceivable that the fairness ratings found were boosted from social desirability in answers, as we, the researchers, played both the roles of choice architect and surveyor. However, influence from social desirability should have been equal across experimental conditions, meaning that relative differences would not have been affected.

It should also be stressed that the present findings likely only hold for situations where the nudge targets a predominantly pro-social behavior. That is, when the nudge encourages a behavior that inflicts a cost on the chooser for the benefit of someone else. If instead the 
intervention facilitates a behavior in the nudgee's apparent self-interest, it seems plausible the nudge would decrease perceived fairness less, if at all.

In conclusion, it is ironic and unfortunate that a choice architect attempting to be more ethical by making a nudge transparent may end up being perceived as less so by the people affected by the nudge. Choice architects may thus face a trade-off between "objective" and "subjective" fairness when implementing nudges - on the one hand catering to theoretically based ethical demands and on the other to the perceptions of affected individuals. We suggest that future research should more closely investigate the determinants of when increased transparency is seen as a sign of positive openness, and when it risk primarily signaling an influence attempt. Understanding how increased transparency affects nudge interventions may provide a key for how to design nudges that are as effective, ethical, and socially sustainable as possible. However, the present findings show that increased transparency is not a silver bullet in the hunt for a nudge intervention that is both effective in changing behavior, and perceived as fair and acceptable by people subjected to it.

\section{References}

Bang, H. M., Shu, S. B., \& Weber, E. U. (2020). The role of perceived effectiveness on the acceptability of choice architecture. Behavioural Public Policy, 4(1), 50-70.

Bovens, L. (2009). The ethics of nudge. In Grüne-Yanoff T. \& Hansson S.O. (Ed.), Preference change (pp. 207-220). Dordrecht: Springer.

Bruns, H., Kantorowicz-Reznichenko, E., Klement, K., Luistro Jonsson, M., \& Rahali, B. (2018). Can nudges be transparent and yet effective? Journal of Economic Psychology, 65, 41-59.

Davidai S., \& Shafir, E. (2020). Are 'nudges' getting a fair shot? Joint versus separate evaluation. Behavioural Public Policy, 4(3), 273-291.

Felsen, G., Castelo, N., \& Reiner, P. B. (2013). Decisional enhancement and autonomy: public attitudes towards overt and covert nudges. Judgment and Decision Making, 8(3), 202213.

Gold, N., Lin, Y., Ashcroft, R., \& Osman, M. (2020). 'Better off, as judged by themselves': Do people support nudges as a method to change their own behavior? Behavioural Public Policy, 1-30.

Hagman, W. (2018). When are nudges acceptable? Influences of beneficiaries, techniques, alternatives and choice architects [Doctoral dissertation, Linköping University Electronic Press].

Hagman, W., Andersson, D., Västfjäll, D., \& Tinghög, G. (2015). Public views on policies involving nudges. Review of Philosophy and Psychology, 6(3), 439-453.

Hedesström, M., Michaelsen, P., Nyström, L., Luke, T. J., \& Johansson, L-O. (2020). What's the net benefit of a nudge? Exploring behavioral spillover from choosing a default. Working paper.

House of Lords, Science and Technology Select Committee. (2011). Behaviour Change (Second report). London, UK: Author. 
Hsee, C. (1996). The evaluability hypothesis: An explanation for preference reversals between joint and separate evaluations of alternatives. Organizational Behavior and Human Decision Processes, 67(3), 247-257.

Hsee, C. K., Lowenstein, G. F., Blount, S., \& Bazerman, M. H. (1999). Preference reversals between joint and separate evaluations of options: A review and theoretical analysis. Psychological Bulletin, 125, 576-590.

Hummel, D. \& Maedche, A. (2019). How effective is nudging? A quantitative review on the effect sizes and limits of empirical nudging studies. Journal of Behavioral and Experimental Economics, 80, 47-58.

Ivanković, V., \& Engelen, B. (2019). Nudging, Transparency, and Watchfulness. Social Theory and Practice, 45(1), 43-72.

Jung, J. Y., \& Mellers, B. A. (2016). American attitudes toward nudges. Judgment \& Decision Making, 11(1), 62-74.

Jung, M. H., Sun, C., \& Nelson, L. D. (2018). People can recognize, learn, and apply default effects in social influence. Proceedings of the National Academy of Sciences, 115(35), E8105-E8106.

Krijnen, J, Tannenbaum, D, \& Fox, C. (2017). Choice architecture 2.0: behavioral policy as an implicit social interaction. Behavioral Science \& Policy, 3(2), i-18.

Lakens, D. (2017). Equivalence tests: a practical primer for t tests, correlations, and metaanalyses. Social Psychological and Personality Science, 8(4), 355-362.

Lakens, D., Scheel, A.M., and Isager, P. (2018). Equivalence testing for psychological research: A tutorial. Advances in Methods and Practices in Psychological Science, 1(2), 259-269.

Loewenstein, G., Bryce, C., Hagmann, D., \& Rajpal, S. (2015). Warning: You are about to be nudged. Behavioral Science \& Policy, 1(1), 35-42.

Michaelsen, P., Johansson, L., \& Hedesström, M. (2020). Experiencing default nudges: autonomy, manipulation, and choice-satisfaction as judged by people themselves. Preprint retrieved from https://psyarxiv.com/utx3e

Oppenheimer, D. M., Meyvis, T., \& Davidenko, N. (2009). Instructional manipulation checks: Detecting satisficing to increase statistical power. Journal of experimental social psychology, 45(4), 867-872.

Paunov, Y., Wänke, M., \& Vogel, T. (2018). Transparency effects on policy compliance: disclosing how defaults work can enhance their effectiveness. Behavioural Public Policy, 3(2), 187-208.

Pe'er, E., Feldman, Y., Gamliel, E., Sahar, L., Tikotsky, A., Hod, N., \& Schupak, H. (2019). Do minorities like nudges? The role of group norms in attitudes towards behavioral policy. Judgement and Decision Making, 12(1), 40-50.

Reisch, L., \& Sunstein, C. (2016). Do Europeans like nudges? Judgment and Decision Making, 11(4), 310-325.

Schmidt, A. T., \& Englen, B. (2020). The ethics of nudging. Philosophy Compass, 15(4), E12658 
Smith, C., Goldstein, D., \& Johnson, E. (2013). Choice without awareness: Ethical and policy implications of defaults. Journal of Public Policy \& Marketing, 32, 159-172.

Steffel, M., Williams, E., \& Pogacar, R. (2016). Ethically deployed defaults: Transparency and consumer protection through disclosure and preference articulation. Journal of Marketing Research, 53(5), 865-880.

Sunstein, C. R. (2016). The ethics of influence: Government in the age of behavioral science. Cambridge University Press.

Sunstein, C. R., Reisch, L., \& Rauber, J. (2017). A worldwide consensus on nudging? Not quite, but almost. Regulation \& Governance, 12(1), 3-22.

Thaler, R. H., \& Sunstein, C. R. (2008). Nudge: Improving decisions about health, wealth, and happiness. New York, NY: Penguin Books.

Yan, H., \& Yates, J. F. (2019). Improving acceptability of nudges: Learning from attitudes towards opt-in and opt-out policies. Judgment and Decision Making, 14(1), 26-39.

Wachner, J., Adriaanse M., and De Ridder, D. (2020). The influence of nudge transparency on the experience of autonomy, Comprehensive Results in Social Psychology: 1-16.

Zlatev, J. J., Daniels, D. P., Kim, H., \& Neale, M. A. (2017). Default neglect in attempts at social influence. Proceedings of the National Academy of Sciences, 114(52), 13643-13648. 